\title{
Public opinion and policy output in the European Union: A lost relationship
}

Dimiter Toshkov, Leiden University, the Netherlands

Corresponding author: Dimiter Toshkov, Assistant Professor, Institute of Public Administration, Leiden University, Wassenaarseweg 52, PO Box 9555, 2300 RB, Leiden, the Netherlands

E-mail: dtohskov@ fsw.leidenuniv.nl;

\begin{abstract}
The European Union (EU) is assumed to suffer from a democratic deficit whereas there is only a weak and indirect connection between public preferences and policy change. This article investigates empirically whether any relationship exists between public support for European integration and EU policy output (1973-2008). Using a new indicator of policy output - the volume of important legislation produced in a semester - I discover a surprising relationship between public support and legislative production. Employing Vector autoregression (VAR) I demonstrate that public EU support Granger-causes legislative output but not vice versa, and that the relationship is strong up to the middle of the 1990s but non-existent afterwards. The effect is robust to the inclusion of indicators of the state of economy and government preferences. In addition, I discover that the average level of EU support in the Council of Ministers follows with a 4-year delay unemployment levels.
\end{abstract}

Keywords

democratic deficit, EU public support, legislative production, policy output, policy change, public opinion, vector autoregression 
Introduction

In a democracy, policy output should reflect the wishes of the public. The European Union (EU) is, however, a most unlikely case to observe policy responsiveness because of the lack of institutional mechanisms linking directly the public and EU policy makers. It is often argued that the EU suffers from a democratic deficit (Follesdal and Hix, 2006) ${ }^{1}$ and that European integration has been driven by elites and has been divorced from the opinions of the broader public (Hellstrom, 2008;

McLauren, 2006). The EU even lacks a demos (Jolly, 2007: 237). In short, the image of the EU as quasi-despotic rule-making machine unchecked by democratic politics is pervasive in academic, media and political discourses alike (Hix, 2008).

Yet, there is only one empirical study (Franklin and Wlezien, 1997) that explores systematically the possibility that public support for the EU and policy activity are somehow related despite the absence of sufficient institutional mechanisms to translate directly mass preferences into policy outcomes. Scholars have mostly assumed that there has been no link between European public opinion and day-to-day policy making in Brussels for the most part of the existence of the EU. Only recently has the EU started to open up to mass politics with the growing power of the directly-elected European Parliament, and the increasing salience of European integration in national political debates (Hooghe and Marks, 2009; Marks and Steenbergen, 2004). Until the late 1970s a 'permissive consensus' allowed European policies to be developed virtually in the absence of any attention by the broader public, and thus any connection to its preferences. After the early 1990s public approval of the EU has been shrinking while the mountain of rules adopted by the EU has continued to rise (see Bechtel and Leuffen, 2010). In fact, the assertion that Brussels is doing too much in the face of ever-declining support for integration is a major tenet and symbolic weapon of Euroskeptics across the continent. 
The main reason why such claims are difficult to evaluate is that we are lacking a reliable measure of EU policy-making activity. The size of the European budget is a poor indicator of the dynamics of European integration because the EU is not a redistributive, but primarily a regulative political system (Majone, 1996; Page and Dimitrakopoulos, 1997). Hence, the amount of significant legislation adopted over time is a prime candidate to provide a measure of EU activity, but existing estimates of the volume of laws produced by the EU are incomplete or unreliable because they bundle together legislative and purely administrative acts. This article addresses this shortcoming by providing a measure of important legislation adopted by the EU over its entire period of existence that is complete, reliable and takes into account the distinctions between various types of EU rules.

Employing legislative productivity as an indicator, the article investigates the link between policy-making activity and public support for the EU for the period 1973-2008. Surprisingly, the analysis finds that policy change follows the ebbs and flows of EU public support. Lower levels of public support are consistently related with lower numbers of important laws adopted, while periods of higher public support are related to periods of more intense legislative activity. Even more surprisingly, the relationship between policy change and public support is strong in the period 19731995 but disappears after that. Given our prior expectations that the EU is gradually opening up to politization and influence by mass preferences since the early 1990s, this finding is truly puzzling (see Jolly, 2007: 233). Using vector autoregressive (VAR) methodology and Granger causality tests, the article demonstrates that the influence flows from public support to policy change and not the other way round. More precisely, legislative productivity is most responsive to public support levels from the preceding year - the lag of the effect makes perfect sense since it provides the necessary time for the policy-making machinery to respond to the changing public preferences. Furthermore, neither general macro-economic factors nor party positions on European integration can account for the link between policy output and public support. Ruling out these potential confounding factors increases our confidence in the existence of a constraining effect of public 
support on legislative productivity in the EU. Despite the absence of institutional mechanisms linking mass preferences and policy change directly, the political system of the EU has been more attentive and more responsive to public sentiment than previously assumed.

In the course of the analysis, I also discover that the average EU affinity of governments in the EU Council of Ministers is positively related to unemployment levels from four years ago. Governments adopt more EU-favorable positions in times of higher unemployment but the effect takes a long time to appear possibly due to election cycles. On the other hand I do not discover any direct effects from the state of the economy and government preferences to public support and on legislative production.

Economic conditions, public and elite preferences, and law production

Mass preferences respond to the positions of political parties and cues provided by political elites. Political parties on the other hand adapt their positions to the changes in public opinion. Shifting economic conditions affect directly both the 'public mood' and party preferences. Governments respond to economic changes by adopting new policies and passing legislation. These policies in turn influence the direction and intensity of public preferences and affect economic conditions.

Each of these propositions is intuitively plausible and at least partly supported by theoretical and empirical research (see below). Taken together they outline a complex and dynamic system with numerous reciprocal and mediated effects. Even if we are interested in only one of the relationships, we have to investigate the dynamics of the entire system. Before turning towards the methodological challenges raised by this complexity, however, the article will offer a more detailed discussion of the possible links between the different parts of the system. 
The relationship of central interest in the present study is the effect of public opinion on policy change, and law production in the EU. While this hypothesis has received little attention in the context of European integration studies, it enjoys a prominent place in the study of the determinants of policy change in the US. Binder (1999) finds an effect of public opinion on legislative gridlock and estimates that "a ten-point jump in public preference for activist government lowers gridlock by 8\%" (p. 529). Coleman (1999) finds evidence that unified government is more responsive to the public mood than divided government. More recently, Grant and Kelly (2008) also look into the effect of the 'public mood' on legislative productivity and confirm the positive influence of public opinion on the various measures of productivity they use. In another study of the effect of public support on legislative output during the first hundred days of US presidential administrations, Frendreis et al. (2001) conclude that greater public support for congressional candidates of the President's party are associated with higher levels of legislative enactments.

The evidence that in the US public support for government action increases the number of adopted important laws is rather strong and univocal. But do we have reasons to believe that the relationship will hold across the Atlantic as well? After all, the EU is a rather different political system channeling public preferences through quite different institutional mechanisms. Members of the European Parliament lack the intimate connection with their constituencies (and the legislative power) that their American counterparts enjoy. Furthermore, in Europe there is no common media and public sphere that can voice and amplify public opinion as in the US. Still, it seems promising that public preferences over government action can overcome the complicated system of checks and balances that the EU and the US share, and affect policy output.

There is no doubt that public support for the EU affects the grand course and contours of European integration (McLauren, 2006). One needs to look no further than the defeat of the proposed European constitution by voters in France and the Netherlands in 2005 in order to see the constraining effects of the lack of broad public support on future efforts to develop European 
integration. In the past, negative public sentiments expressed in referenda have led Norway to remain outside the EU (twice - in 1972 and 1994) and Denmark outside the common currency area (2000). Referenda in Ireland retarded the ratification of the Treaty of Nice (2001) and the Treaty of Lisbon (in 2008). What is more controversial and much less researched is whether public opinion and support affect day-to-day policy making in Brussels.

There are some clues that routine policy making, and as a result the volume of legislation produced by the EU, is affected by the ups and downs of public opinion. For example, Hix (2008) argues that between 'the mid-1980s and the mid-1990s, the EU was able to pass a large amount of legislation because there was overwhelming support for changes to existing policies' (p. 32) but there has been no proper test of this argument. Anecdotal evidence of the EU scrapping proposed laws in times of unfavorable public opinion exists. For example, in 2009 the European Commission postponed a proposal to have wills and inheritance claims recognized across member states because of 'fear of negative reactions in Ireland ahead of the crucial [second] referendum' on the Lisbon Treaty. Similarly, the decision of the Commission to halt a proposal on corporate tax in 2009 was linked to the same fear of irritating Irish public opinion (Crosbie 2009). In another case, in September 2005, amidst the ratifications of the ill-fated EU constitution, the Optical Radiation/Sunshine Directive caught public attention as an example of some of the more absurd policy proposals awaiting adoption by EU. Angry reactions from an already hostile public ignited opposition in the EP and led the Commission to exclude natural radiation form the scope of the directive. $^{2}$

The accumulation of such minor incidents should be enough to affect legislative output in the aggregate. The effect does not even need to be intentional or coordinated. Individual decisions by various actors can add up to affect the size of the legislative agenda, the likelihood that proposals will be approved, and the time it takes to adopt a legal act. The Commission might postpone or halt altogether the introduction of some new policy initiative. Committees in the EP or working groups 
in the Council of Ministers might spend more time discussing existing proposals. Governments in the Council can delay or block the adoption of legislation not to infuriate an already negative public. On the other hand, high support by the population will embolden the Commission to come up with new initiatives and will provide a mandate for governments to agree on the common policies. The 'response' to public opinion need not be explicit. It might be masked in programs like the 'Better Regulation' initiative, which aims to cut down the volume of legislation adopted and in force in the EU (European Commission, 2005).

The causal mechanisms through which the effect of public opinion on policy change might be exercised involve the behavior of the Commission in its agenda-setting capacity, and the Council with its working groups, as the main legislator. The Commission might reduce the number of policies it proposes in times of low public support for the Union for ideological and strategic reasons. Commission officials might be ideologically predisposed to propose fewer EU rules if they perceive that the public legitimacy of the EU is low. They might also reduce the number of initiatives in times of low support as to avoid a backlash by an already hostile public or an irritated Council. Similarly, Council officials might delay or block new EU legislation when public support is declining because they feel that the EU lacks a mandate for new initiatives, or because they fear the negative reaction of the public.

The discussion so far provided comparative insights from the US and suggested causal mechanisms that make a link between public support and legislative output in the case of the European Union plausible. It is equally likely, however, that legislative activity exerts a reciprocal effect on public preferences for integration. After periods of little activity at the EU level the public will increase its support for the EU and express preferences for more European policies. As more and more legislation is produced, the public will feel overwhelmed by the amount of the rules coming from Brussels and decrease its levels of support. This view is related to the most comprehensive theoretical account of the dynamic links between public opinion and policy changes 
provided to date by the 'public as thermostat' idea (Wlezien, 1995, 2004). The theory predicts that when the level of policy differs from the public's most preferred level, the public will favor a change in policy in one direction or the other. Once policy makers change the policy and if the public is responsive, the public would adjust its preferences. "In effect the public will behave like a thermostat, where a departure from the favored policy temperature produces a signal to adjust policy accordingly, and once sufficiently adjusted, the signal stops" (Wlezien, 1995: 982). Franklin and Wlezien (1997) found that 'as the salience of the European domain has increased, public responsiveness to policy has followed' (p. 360). Importantly, they argue that since the 1980s the public has reacted 'with precision and almost instantaneously' to the EU legislative output. However, the study does not allow for the possibility that the public actually influences policy output rather than reacts to it. Furthermore, the analysis fails to model the autoregressive nature of the public opinion time series, therefore overestimating the effect of the explanatory variables, including legislative output. While later in this article I will establish that public preferences and legislative production are indeed related, I will reach quite different conclusions about the causal structure behind the link by using more appropriate methodological tools.

\section{The state of the economy and party positions}

Public opinion and policy change do not move in isolation over time. Each is influenced by numerous other factors, including the institutions of the political system, reactions to current events, etc. While presenting a comprehensive model of either public opinion or policy change is beyond the aims of this article, I consider factors that could simultaneously influence both public opinion and policy, thus possibly 'explaining away' a link between these two. The general state of the economy and party positions are the primary candidates for such confounding variables. There is enough evidence to attest that the health of the economy affects public opinion (Clarke et al., 1993; Erikson et al., 2002) and support for EU integration in particular (Handley, 1981; Eichenberg and 
Dalton, 1993; Anderson and Kaltenthaler, 1996; Anderson and Reichert, 1995; Franklin and Wlezien,1997) and some reasons to suspect that it affects the amount of legislation adopted over time. As for party positions, in the case of EU support mass and party positions have been shown to be entangled in a complex interplay (Hellstrom, 2008; Carrubba, 2001, Wessels, 1995; Schmitt and Thomassen, 2000). At the same time it is more than plausible that (government) party positions affect policy making in Brussels (Golub, 1997; Golub and Steunenberg, 2007; Schulz and König, 2000).

[Figure 1 about here]

Figure 1 summarizes the discussion of the possible links between economic conditions, public opinion, party positions and policy change (law production). Solid arrows represent links for which evidence exists from studies of the EU, while dotted arrows represent hypothesized relationships for which only anecdotal or comparative evidence from the US is available. The figure makes clear that we have very little reason to a priori exclude many of the possible relationships. Furthermore, there is very little theory that provides strong expectations about the temporal order of the four factors. We should also note that notwithstanding the causal links summarized in the figure, in many cases the best predictors of the values of economic conditions, public opinion, and party positions are simply their lagged values. Furthermore, it is important that, with the possible exception of the impact of the economy on public opinion, most relationships are not instantaneous. Hence, we need an analytical framework that allows for autoregressive, reciprocal and mediated relationships. Vector autoregressive models (VAR) provides such a method. But before I turn to the elaboration of the statistical model, the article will present the operationalization and the data sources on which the empirical part of the article is based. 
Data and operationalization

This article seeks to understand the determinants of legislative production. Legislative production, or output, is a major marker and component of the more abstract concept of policy change.

Especially in the case of the EU with its weak redistributive capacities, legislative output is the most important indicator of policy activity (Page and Dimitrakopoulos, 1997). Since the EU is a polity in the making, policy activity is often related to the transfer of policy making from the nation-state to the supranational level.

Legislative output is operationalized as the number of directives adopted by the EC/EU in each half-year period (i.e. semester). ${ }^{3}$ In the EU legal system directives, regulations, and decisions are quite different instruments in terms of aims, scope, importance, and use (Bast, 2003). The main legislative acts of the EU are directives and most important regulatory initiatives in the EU take the form of directives. In terms of goals, scope and importance, directives are closest to laws in national legal systems. Although regulations can be also very important and raise controversies between the member states (König, 2008), most of them deal with rather routine management tasks. It is important to take this distinction into account, especially since the number of adopted regulations dwarfs the number of directives. Presenting together directives and regulations is in practice almost the same as presenting only regulations, which is problematic if we are interested in genuine policy change. Furthermore, unlike current practice, I exclude Commission directives from the scope of important EU legislation. ${ }^{4}$ Commission directives are implementing acts that further specify or update provisions laid down in 'regular' directives and as such do not have a place in an index of important legislation. Of course, there are some important and consequential regulations, decisions, and Commission directives that affect that lives of European citizens and the fortunes of European companies. Focusing on non-Commission directives, however, provides a transparent and replicable 
way of delineating salient policy output while avoiding having to judge the importance of each EU decision individually.

The number of directives in each semester is derived through automatic data extraction from the EU's legislative database EURLEX, the scope of which is comprehensive for the study period of 1973-2008 (for a discussion of EURLEX see König et al., 2006). Collecting individual-level information and aggregating over semesters only afterwards, I avoid some problems with relying on the built-in query capabilities of the database. Moreover, I exclude legal acts based on the Judicial Co-operation and Common Foreign Policy pillars of the EU because in these domains the decisionmaking modes and the types of legal acts are rather different.

Since the level of aggregation can have consequences for time series statistical modeling, some justification for the chosen unit of analysis is needed. Opting for semesters as the unit of analysis makes sense in view of the institutional structure of the EU. The Presidency of the European Union is organized in half-year cycles. The rhythm of the changing Presidency sets the rhythm for the meetings of the various formations of the Council of Ministers. Many of the Council formations meet more than twice a year; others, however, do so only at the end of the Presidency terms. I want to assess the legislative productivity for a period that is short enough to capture shortterm fluctuation but at the same time long enough to even out uninteresting variation stemming from the irregularity of the meetings of the Council. Examination of the monthly data confirms the existence of half-year cycles and supports the decision to aggregate over semesters.

The topmost panel of Figure 2 plots the number of directives adopted by the EU over time. While the picture corresponds roughly with received wisdom about the ups and downs of the European integration process, there are a few things to note. The period of stagnation during the 1970s seems much less dramatic when EU activity is measured precisely (see Golub, 1999; Franchino, 2007). Excluding the surge in legislation coming with the Single European Act (SEA), the mean number of directives does not seem to have changed much since the late 1970 s. We can 
also notice that the behavior of the series is getting much more erratic over the last few years. More details about the statistical properties of the time series will be presented later in the article.

[Figure 2 about here]

Public support for European integration is the next main variable used. Public support as an aspect of public opinion is especially relevant for our discussion, because it taps into the overall legitimacy that the European project enjoys. Luckily, a measure of public support for integration that goes back to 1973 exists and since then it has been measured twice each year. The measures collected by the Eurobarometer are based on representative samples for each of the EU member states and the final figures reflect a weighted EU average. The precise operationalization of support is the percentage of respondents considering membership of their country in the EU 'a good thing., 5 This question provides the longest uninterrupted time series from the entire Eurobarometer survey and has been shown to be highly correlated with the desired speed of integration and other citizen assessments of the EU. Conveniently, the question is posed in the spring and autumn editions of the "Standard Eurobarometer" which matches the unit of analysis of the legislative output variable.

The second part of Figure 2 plots the movement of public support for integration over time. The story that the plot tells is a well-known one with higher values of support before the beginning of the 1990s when the level of supports drops and never quite recovers to the levels of the 1980s. The band within which public supports varies is between 40 and $70 \%$ active support for the EU.

The operationalization and measurement of party influence is less straightforward. First of all, we have to choose which institutions to take into account. I opt to exclude the Commission, because it is supposed to be non-partisan and to act in the general interest of the Community, and because of the lack of measures of the ideological preferences of Commissioners over time. I also exclude the European Parliament from consideration. I am not oblivious to the increase in its 
powers over time, but as of now the EP is still not a co-legislator in all policy areas. Even its powers in the domains where the co-decision procedure applies have been granted only after 1992. As a result, I focus exclusively on party (government) preferences within the Council of Ministers which is the main decision-making institution in the EU. In line with our operationalization of public support, the focus is on European integration positions, and thus not on substantive policy preferences.

I construct a measure of the Council's level of support for European integration for the period 1973-2008 (cf. Franchino, 2007; Warntjen 2007; Warntjen et al. 2008). The following procedure applies. First, I estimate the EU support of each national political party according to the data provided by the Comparative Manifestos Project (Budge et al., 2001; Klingermann et al., 2007). The estimates are based on content analysis of the manifestos of political parties. ${ }^{6}$ The specific EU support variable is created by subtracting all hostile statements concerning European integration from all favorable mentions. Second, I create government positions by weighting the position of each party in the national government by the proportion of parliamentary seats it holds. Third, I compute an EU-wide weighted average of the national government positions. Two measures per year are taken. The aggregate EU measures are created by weighting the position of each national government by its share of votes in the Council of Ministers. Although consensus has been the prevailing mode of decision making in the EU for much of its existence, I expect that the influence of each member state is roughly proportional to its voting power, although votes might rarely be taken.

The third panel of Figure 2 traces the movements of the Council's European integration support over time. After a period of steady growth starting in 1974, the average weighted support of EU governments peaks in 1992, after which it declines. A second heap culminates in 2001 but support drops steadily afterwards. 
I focus on unemployment in order to capture the effect of economic conditions. Rising unemployment most directly hurts people's evaluations of their well-being and is most likely to affect their attitudes and opinions towards governance. From the range of options to tackle the impact of the changing economy I also considered the Misery Index (Franklin and Wlezien, 1997). Inflation in the EU, however, has been subject to two quite different policy regimes before and after the introduction of the common currency. Also, the negative effects of inflation on citizens are not as straightforward to discern as the effects of unemployment. I rely on OECD estimates of unemployment levels ${ }^{7}$. The bottom panel of Figure 2 plots the development of the average unemployment levels in the EU.

Method of analysis

Multivariate autoregressive models (VAR) provide an approach to model dynamics among a set of possibly endogenous variables. In VAR models each variable is a function of its past values and the past values of the other variables in the system (Brandt, 2007; for Bayesian VAR see Brandt and Freeman, 2009). A major advantage of VAR is that it places few restrictions on the data and the parameters of the model. The following set of equations provides a representation of the full model tested in this article:

EQUATION 1 about here

Effectively, each of the four variables is regressed on its own $p$ lagged values and the $p$ lagged values of each of the remaining variables. The same number of lags is included for each variable in each equation. The errors (the residuals) are assumed to be jointly normally distributed. Note that 
no contemporaneous relationships can be included in the system - present values of public support are not allowed to influence present values of policy output as this would imply serial correlation between the errors. Since political relationships are mediated by institutions (see the previous section) and thus lagged, this assumption is not problematic for the current analysis.

The VAR approach is composed of three steps: (1) assess the causal effects of the endogenous variables on each other, (2) investigate the dynamic impact of variation in one variable on the others, and (3) estimate the amount of variance in one variable brought by changes in every variable (Brandt, 2007). I now turn to each of these tasks in turn. Initially, I examine a two-variable VAR focusing only on the interactions between public support for integration and legislative output. After that, I present a four-variable VAR in order to test the robustness of the obtained results and to investigate the rest of the relationships suggested by the theoretical overview.

Results from the empirical analysis

To start the analysis, Figure 3 plots the normalized (the mean is set to zero) levels of public support and a 5-point moving average of the normalized levels of legislative output (number of directives adopted) in the EU from the second semester of 1973 until 2008.

[Figure 3 about here]

The link between the two series is astounding. It is further emphasized by the very similar scale of the variances (which have not been standardized). The general movements of the two variables are so synchronous that it is hard to believe they measure two such different concepts. It should be recalled that I juxtapose a measure of rather general public preferences aggregated over a 
geographical area spanning from 9 (1973) up to 27 (2008) countries and a measure of policy change that is as specific as it gets - the number of important legislation (directives) adopted by the EU.

The bottom part of Figure 3 presents the cross-correlation function (CCF) of the two time series. The CCF 'compares' one time series with an increasingly delayed version of the other (Cryer and Chan, 2007). It is useful for checking at which lag the cross-correlations peak. In this case, we can see that the greatest value (the highest spike) is at lag $-2^{8}$. Determining how many lags to include in VAR is an important modeling decision. Comparing the information criteria of models with increasing lags shows that two lags should be included which is in line with the insight from the $\mathrm{CCF}$.

The results of the estimation of the equations using OLS are reported in Table $1 .{ }^{9}$ The coefficients from Table 1, however, cannot be interpreted individually, "because it is the behavior of the system and all its coefficients that describe the dynamics of the variables" (Brandt, 2007, p. 65). In order to assess the causality in the system, I perform Granger causality tests. These tests examine the hypothesis that the behavior of the past of one variable $\mathrm{Y}$ can better predict the behavior of another variable $\mathrm{Z}$ than the past of variable $\mathrm{Z}$ alone (Granger, 1969). Table 2 reports the results. The first row tests the conjecture that public support Granger-causes legislative output. The F-statistics indicates that we can refute the null hypothesis of no causation with a great degree of confidence. On the other hand, the conjecture that legislative output Granger-causes public support receives only very weak support since the p-value is almost exactly at the edge of conventional statistical significance criteria (0.05). Hypotheses of instantaneous causality are refuted using Waldtype tests. We can conclude that information from the past values of public support improves our predictions of the behavior of legislative production. ${ }^{10}$

[Table 1 about here] 
[Table 2 about here]

The most useful way to describe the dynamics of a VAR system is to examine the impulse response function (IRF). The IRF traces the impact over time of a shock to the VAR residuals on the variables in the system (Brandt, 2007). Figure 4 plots the IRF and shows that a shock (one standard deviation) to public support leads to a short-lived significant increase in the level of legislative output. The cumulative effect is maximized at lag 3 and dies off afterwards. A shock in legislative output leads to a more prolonged response in public support which is however not significantly different from zero, as indicated by the $95 \%$ bootstrapped confidence intervals enveloping the response function. In addition, the IRF is sensitive to the existence of unit roots and trends in the data (see below) and should be interpreted conservatively.

Finally, we can interpret the dynamic relationships in the VAR system by decomposing the forecast error variance (FEVD). This technique estimates the amount of variation in each variable that can be attributed to changes in its own past values and in the values of the remaining variables over a period of time. From the examination of the FEVD of legislative output (not shown) we can conclude that after five time periods approximately $15 \%$ of the variation in legislative output can be attributed to the influence of public support. In substantive terms, public opinion accounts for $+/-$ three directives per year.

These results appear promising, but we have to consider possible threats to the validity of the conclusions of the analysis. A major concern in time series analysis is stationarity. A time series is stationary if it has a constant mean, a constant variance and the covariance between observations is a function of only how far apart they are in time, not the time at which they occur. Failures to account for non-stationarity (i.e. presence of unit roots) might lead to spurious results because 
standard significance tests are misleading. In general, in case of non-stationarity differencing the data is recommended. In the context of VAR models, however, 'data transformations that difference the data to revoke trends should be avoided' (Brandt, 2007: 49). Differencing removes important temporal variation that is of substantive interest to the analysis. In cases of co-integration (see below) "differencing the data will be counterproductive, since it would obscure the long-run relationship between $\mathrm{y}_{\mathrm{t}}$ and $\mathrm{x}_{\mathrm{t}}$ "(Greene, 2003: 650).

[Figure 4 about here]

In the case of political and policy data, it is even argued that non-stationary processes are theoretically impossible. Percentage and index-based variables, such as public opinion measures or ideology scores for example, are bound from below and above and cannot 'explode' outside these limits as real non-stationary variables could. Since time series in political science are usually short, it has been suggested that what is often taken as unit roots are only short-term trends (Brandt, 2007).

These debates notwithstanding, I tested the public support and legislative output series for non-stationarity. The Augmented Dickey-Fuller (ADF) test does not find evidence to reject the nonstationarity hypotheses for legislative output, and for public support. There is no evidence for autocorrelation in the Output series, however. Looking back at Figure 3 we can easily dismiss deterministic trend stationarity but we can not exclude random walks behavior from both series. In principle, regressing two non-stationary series on each other might lead to spurious correlation (Granger and Newbold, 1974). However, if there is co-integration between the two variables, the resulting system will be stationary and as a result the test statistics will be asymptotically valid (Engle and Granger, 1987). I tested public support and legislative output for co-integration and the p-value of 0.037 provided by the Phillips-Ouliaris co-integration test (Pfaff, 2008) shows that the null hypothesis of no co-integration can be refuted. The implication of co-integration is that the 
series are drifting together at roughly the same rate (Greene, 2003: 650). Furthermore, I tested the residuals of the VAR regressions for stationarity and the ADF indicates that there is no unit root. Altogether, I conclude that even if there is non-stationarity in the individual variables, the VAR results are valid due to co-integration.

The analysis so far has been conducted with the entire set of observations covering the period 1973-2008. A closer look at Figure 3, however, suggests that a change in the relationship between public support and legislative production might be happening around the year 1995. While public support continues to fall, levels of legislative output increase and remain higher than their level suggested by the equilibrium relationship before 1995. In order to examine the temporal consistency of the link between support and output, I re-did the VAR analysis using the subsample of observations until $1995(\mathrm{n}=44)$. The Granger causality tests provide even stronger evidence for a causal impact of public support on legislative output, but all traces of a possible effect in the other direction have disappeared (the p-value is 0.32 ). The forecast error variance decomposition suggests that after 5 time periods more than $22 \%$ of the variation in legislative output can be attributed to shocks in public support. On the other hand, when I replicate the analysis with the subset of observations from 1995 to 2008 , the only relationship that I can discover is the dependence of public support on its past values.

Why does the time around 1995 constitute a watershed? Two events in the grand history of EU integration can be related to the rupture: the accession in 1995 of Austria, Finland, and Sweden, and the entry into force in 1993 of the Maastricht Treaty which significantly changed the EU by adding two new 'pillars' to its domains of responsibility. The 1995 Enlargement can reasonably be related to decreases in levels of public support because the citizens from the new member states pushed down the overall levels of EU support and it might have changed the dynamics of public opinion. But the results from the analysis suggest that the link between support and policy output had been broken in that period. The Maastricht Treaty expanded the powers of the EP by 
introducing the co-decision procedure and generally led to higher visibility and salience of European integration for the broader public (Jolly, 2007). Therefore, it is truly astonishing that the relationship between public preferences and policy change disappears during the period instead of getting stronger. I hypothesize that EU policy makers might have felt that now that the EP has a real bite in decision making, they no longer need to stay attuned to survey measures of public opinion. It could also be that the volume of EU legislation had accumulated enough critical mass to require a considerable number of new rules just to keep it up-to-date, generating a dynamic of its own. The 1995 rupture is puzzling but more recently the dynamics of the process has changed yet again. Since 2004 the levels of legislative output make another turn and actually fall below public support levels. Certainly, extraordinary events like the crisis surrounding the investiture of the Barroso Commission (2004) and the two rounds of enlargement in 2004 and 2007 (for the effect of enlargements on legislative production see Leuffen and Hertz, 2010) might account partly for the low levels and extremely erratic behavior of legislative productivity in that period. Conscious restraint on the part of the Commission to introduce and pursue new legislation, however, has also a great deal to do with this recent structural change in the time series, as demonstrated by the examples earlier in this article (see for example the Better Regulation program mentioned earlier in the article).

So far the analysis examined EU public support and policy change in isolation. The bivariate VAR uncovered interesting results, but it is still necessary to check the behavior of the larger system outlined in the theoretical section in order to assess the robustness of the results. It is not my purpose to investigate comprehensively the entire system of interactions between the economy, mass preferences, political parties and policy change in this article. Nevertheless ,I need to broaden the scope of the previous analysis in order to avoid under-specification of the statistical model. In the following pages I present a four-variable VAR that adds unemployment and the average EU support in the Council of Ministers to public support and legislative output. Due to missing values I restrict the study period until the end of 2003 (61 observations). 
Looking first into the behavior of the unemployment and party positions over time, the CCF (not shown) suggests an extremely interesting positive correlation between the series at lag 8 (corresponding to 4 years). The relationship can also be spotted in the lower two panels of Figure 2 . This result suggests that the average sympathy of national governments for the EU reflects with a 4years delay the ups and downs of unemployment levels. I will have more to say on that later in the article.

Before presenting the results from the VAR analysis, I test for stationarity and co-integration and select the appropriate number of lags to be used in the model. Unemployment and party positions are both non-stationary, according to the ADF tests. At the same time, the PhillipsOuliaris Co-integration Test finds no evidence of co-integration in the system. As a result, one should be careful in interpreting the results from the VAR estimations because the presence of unit roots in the system might produce spurious results.

Similarly to the bi-variate case, the Akaike Information Criterion suggests using two lags in estimating the system. Table 3 summarizes the results from the Granger Causality Tests for each pair of variables. In addition to the effect of public support on legislative output, there is some evidence that unemployment levels are related to the average support for the EU in the Council of Ministers. The IRF and error decomposition plots (not shown) confirm the lack of additional significant effects in the system.

The most important conclusion from this part of the analysis is that the link between public opinion and policy output does not disappear after including two likely confounding variables in the system. In fact, public support is exogenous to the system according to the results. But can more be said about the ups and downs of government positions? The VAR(4) results and further data exploration suggest that the mean level of EU affinity in the Council tracks with a 4-year delay average unemployment levels in the EU. Rising unemployment leads to higher EU support in the Council after a period of approximately one election cycle. While this relationship is interesting, it 
is beyond the scope of this article to explore in detail the possible link between government preferences in the Council and economic conditions.

\section{Conclusion}

The main finding of this article is that public support for European integration is related to the legislative output of the EU. In times of higher levels of citizens' support for EU membership, a higher number of important laws have been adopted. The volume of legislation reacts with a one year lag to the movements of public opinion and the accumulated effect of public opinion contributes as much as $20 \%$ of the variation in policy output. The relationship, however, only survives until the middle of the 1990s, after which the paths diverge. Legislative production does not fall as deeply as public support for the EU and due to the EU constitutional developments in that period becomes extremely unstable. This set of conclusions directly contradicts received wisdom about the lack of any link between day-to-day policy making in the EU and the attitudes of the European citizens until the 1990s, and a gradual opening of policy making to mass sentiments only since that period. It would seem that policy makers in the EU have been much more attentive to movements in public opinion than previously suggested despite the lack of institutional mechanisms making them directly accountable to the public at large. It is as if policy makers' decisions track the ebbs and flows of public opinion in at attempt not to stray too far away from the amount of perceived legitimacy of the EU in the eyes of the public. The implications of this finding for the debate about the democratic legitimacy of the EU are obvious.

Many questions about this relationship remain unanswered. The most pressing one is why the link disintegrates in the 1990s. Legislative inertia, or 'substitution' of covert attentiveness to public opinion by the more direct accountability mechanism provided by the EP are likely candidates, but more research is needed to address this issue. Looking into specific policy areas might provide a useful research strategy. Investigating whether the aggregate-level relationship 
holds, for example, in the field of environmental policy, and examining the dynamics of the volume of Commission legislative proposals over time can provide further insight into the process and its temporal structure.

Overall, the article discovered two pairs of variables that move together: public support for integration with legislative productivity, and unemployment with government positions. There is no evidence in the data that the two sub-systems are related over the entire period studied in this article. Restricting our horizon from the beginning of the 1980s to the beginning of the 1990s, the four series move quite synchronously. Unemployment leads, followed by public opinion, government positions and finally policy output. Since the beginning of the 1990s, however, once all four series start moving down, their paths split. Unemployment takes a shallow dip but quickly recovers. Government positions react similarly and by 2000 they are back on the levels before the ‘crisis'. Public opinion, however, takes a deeper plunge and never quite achieves the peak levels of support from the end of the 1980s. The path followed by legislative production is intermediate: the volume of new laws adopted does not reach its peak levels, like in the case of party positions, but the dip is not as deep as in the case of public opinion.

Curiously, much of the previously made claims about a link between aggregate economic indicators and mass EU support rely on data from the relatively short period when their paths diverge (1985-1995) (Anderson and Kaltenthaler, 1996; Eichenberg and Dalton, 1993). Scholars have taken the contemporaneous movements in opposite directions during that period as evidence that worsening economic conditions push levels of mass support to the EU down (Anderson and Kaltenthaler, 1996; Eichenberg and Dalton, 1993). This reaction would seem logical but it does not hold before and after this period. In light of the positive correlation discovered between government EU positions and lagged unemployment, it is entire possible that public support also reacts on previous levels of unemployment, or just that their synchronous movement in that decade is entirely 
due to chance. Future research can disentangle the links between public opinion, party positions, and the economy by diachronic analyses of single countries.

Much of the theoretical insights on which this article is based come from the study of US politics and government, so it is instructive to see how the findings of the analysis compare to what is known about the dynamics of the American macro polity. In a monumental study published in 2002, Erikson, MacKuen and Stimson advance several claims: economic performance moves macro-partisanship and policy mood; these two influence policy activity; and policy activity affects future levels of unemployment and inflation (Erikson et al., 2002). How is the EU polity different at the system level from the American one? The relationship between public support for government activity at the federal/EU level and policy output is present in both polities. The positive effect of worsening economy for party preferences for federal/EU policy intervention is similar. What is missing in the EU is the link between the party preferences and policy output, and the influence of policy output on the economy. In view of the extremely opaque policy-making structure in the EU, it is not so surprising that the average position in the Council is not directly related to the amount of important legislation produced. But since this crucial link is not in place, the relationship between the state of the economy and policy change is absent as well. The contrast between the responses of the US and the EU to the current financial and economic crises are illustrative in this respect - the US adopted relatively quickly several important packages of new legislation while the EU, constrained by low public support, has produced little in terms of new policies. 
Notes

${ }^{1}$ Skeptical opinions about the existence of a democratic deficit have been expressed by Crombez (2003) and Moravcik (2002). For a recent overview of the debate surrounding the concept see Follesdal (2006).

${ }^{2}$ The initial proposal contained rules governing the exposure of employees to cancer-causing sun rays. In that particular case, the legislation was eventually adopted, but only because the issues of artificial and natural radiation could be separated.

${ }^{3}$ Existing measures of EU legislative output suffer from serious shortcomings. Many studies fail to distinguish between the various types of EU legal acts and, as a result, decrease the internal validity of the measure of legislative productivity. (Alesina et al., 2005; Selck et al., 2007). Other estimates do not cover a sufficient scope of the EU activities over time and across policy sectors (Page and Dimitrakopoulos, 1997).

${ }^{4}$ Another reason to exclude Commission directives from the sample is that many Commission directives are 'required' by acts of the Council, or the Council and the Parliament acting together. Furthermore, many of these directives concern minor modifications or updating to technical progress already existing legislation. In effect, the Commission has much less discretion whether to propose and adopt these acts. Also, partly because of this automatism, the number of Commission directives grows over time for the period investigated in this article.

${ }^{5}$ The wording of the question is "Generally speaking, do you think that (OUR COUNTRY)'s membership of the European Union is...?" and the possible answers are 'a good thing', "neither good nor bad', "a bad thing". Some scholars prefer to measure 'net' support by subtracting negative from positive answers. Since the remaining category contains undecided respondents as well as those who declined or for any other reason did not deliver an answer, we decided against using 'net' support as a variable. 
${ }^{6}$ An alternative would have been to use one of the several expert surveys of party positions available (Benoit and Laver, 2006; Marks et al., 2006). Given the long time span of the current analysis, however, we believe that the Comparative Manifestos approach offers more reliable estimates. While it is common practice to extrapolate party positions from surveys taken in the 1990s for a few year ahead or back in time, using the expert scores for party positions during the 1970s and early 1980s is problematic. After all, it was a change of the position of the French Socialist Party rather than a change in government that made the French support the SEA.

${ }^{7}$ OECD defines unemployment as the numbers of unemployed persons as a percentage of the civilian labour force (civilian labour force consists of civilian employees, the self-employed, unpaid family workers and the unemployed). The mean of the two first quarters provided measures for semester I and the mean of the last two quarters for semester II of each year. I weighted the country figures provided by the OECD by population to create the EC/EU aggregate level.

${ }^{8}$ Formally, the cross-correlation function is maximized at lag [-2] with a numerical value of 0.44 with the nearest competitor lag [1] having a value of 0.39 . Lag [-2] corresponds to the correlation between Public Support [t-2] and Legislative Output [t].

${ }^{9}$ The model is stable. The auto-correlations and the partial auto-correlation functions of the residuals of both equations do not show any significant auto-correlation. A test of the stability of the whole system does not indicated problems since the moduli of the eigenvalues of the companion matrix are all less than one (Pfaff, 2008).

${ }^{10}$ A note about the temporal sequence and plausibility of the relationship: Let us take as an example the Standard Eurobarometer Number 52. It is published in 2000 and the field work is conducted in October and November 1999. In our database it will feature as an entry for the second semester of 1999. Since we focus on two lags (which correspond to one year), the number of legislation published between July and December 1999 appear de facto related to levels of public opinion from 
October-November 1998. Since the average life-time of a directive between proposal and adoption is approximately 2 years and the median duration is 18 months (data available on request), it means that the substantive negotiations of directives coincide with the levels of public opinion to which the overall volume 'responds'.

\section{References}

Alesina A, Angeloni I and Schuknecht L (2005) 'What Does the European Union Do?', Public Choice 123(1): 275-419.

Anderson C J and Kaltenthaler K C (1996) 'The Dynamics of Public Opinion toward European Integration, 1973-93', European Journal of International Relations 2(2): 175-99.

Anderson C J and Reichert M S (1995) 'Economic Benefits and Support for Membership in the E.U.: A Cross-National Analysis', Journal of Public Policy 15(3): 231-49.

Bast J (2003) 'On the Grammar of EU Law: Legal Instruments', Jean Monnet Working Paper 9(03): $1: 73$.

Bechtel M and Leuffen D (2010) 'Forecasting European Union Politics: Real-Time Forecasts in Political Time Series Analysis ', European Union Politics 11(2): 309-27.

Benoit K and Laver M (2006) Party Policy in Modern Democracies. London: Routledge.

Binder S A (1999) 'The Dynamics of Legislative Gridlock, 1947-96', American Political Science Review 93(3): 519-33.

Brandt P T (2007) Multiple Time Series Models. Thousand Oaks: Sage Publications.

Brandt P T and Freeman J R (2009) 'Modeling Macro-Political Dynamics', Political Analysis 17(2): $113-42$. 
Budge I, Klingermann H-D, Volkens A, Bara J and Tanenbaum E (2001) Mapping Policy Preferences: Estimates for Parties, Electors, and Governments 1945-1998. Oxford: Oxford University Press.

Carrubba C J (2001) 'The Electoral Connection in European Union Politics', The Journal of Politics 63: $141-58$.

Clarke H D, Dutt N and Kornberg A (1993) 'The Political Economy of Attitudes toward Polity and Society in Western European Democracies', The Journal of Politics 55(4): 998-1021.

Clingermann H-D, Volkens A, Bara J and Budge I (2007) Mapping Policy Preferences Ii: Estimates for Parties, Electors and Governments in Central and Eastern Europe, European Union and OECD 1990-2003. Oxford: Oxford University Press.

Coleman J J (1999) 'Unified Government, Divided Government, and Party Responsiveness', The American Political Science Review 93(4): 821-35.

Crombez C (2003) 'The Democratic Deficit in the European Union - Much Ado About Nothing?', European Union Politics 4(1): 101-20.

Crosbie, J (2009) 'Irish treaty vote puts inheritance law on hold', European Voice, 14 May 2009.

Cryer J and Chan K-S (2007) Time Series Analysis. With Applications in R. Second Edition. New York: Springer.

Eichenberg R C and Dalton R J (1993) 'Europeans and the European-Community - the Dynamics of Public Support for European Integration', International Organization 47(4): 507-34.

Engle R and Granger C (1987) 'Co-Integration and Error Correction: Representation, Estimation, and Testing', Econometrica 55(2): 251-76. 
Erikson R S, Mackuen M B and Stimson J A (2002) The Macro Polity. . Cambridge: Cambridge University Press.

European Commission (2005) 'Better Regulation for Growth and Jobs in the European Union', $\{\operatorname{SEC}(2005) 175\}$.

Follesdal A (2006) 'Survey Article: The Legitimacy Deficits of the European Union', Journal Of Political Philosophy 14(4): 441-68.

Follesdal A and Hix S (2006) 'Why There Is a Democratic Deficit in the EU: A Response to Majone and Moravcsik', Jcms-Journal Of Common Market Studies 44(3): 533-62.

Franchino F (2007) The Powers of the Union. Cambridge: Cambridge University Press.

Franklin M N and Wlezien C (1997) 'The Responsive Public - Issue Salience, Policy Change, and Preferences for European Unification', Journal Of Theoretical Politics 9(3): 347-63.

Frendreis J, Tatalovich R and Schaff J (2001) 'Predicting Legislative Output in the First OneHundred Days. 1897-1995', Political Research Quaterly 4: 853-70.

Golub J (1997) 'In the Shadow of the Vote? Decisionmaking Efficiency in the European Community 1974-1995', MPIfG Discussion Paper 97/3.

Golub J and Steunenberg B (2007) 'How Time Affects EU Decision-Making', European Union Politics 8(4): 555-66.

Granger C (1969) 'Investigating Causal Relationships by Econometric Models and Cross-Spectral Methods', Econometrica 36: 424-38.

Granger C and Newbold P (1974) 'Spurious Regresssions in Econometrics', Journal of Econometrics 2(2): 111-20. 
Grant J T and Kelly N J (2008) 'Legislative Productivity of the U.S. Congress, 1789-2004', Political Analysis 16(3): 303-23.

Greene W H (2003) Econometric Analysis. Fifth Edition.: Pearson Education.

Handley D H (1981) 'Public Opinion and European Integration: The Crisis of the 1970s', European Journal of Political Research 9(4): 335-64.

Hellstrom J (2008) 'Who Leads, Who Follows? Re-Examining the Party-Electorate Linkages on European Integration', Journal Of European Public Policy 15(8): 1127-44.

Hix S (2008) What's Wrong with the European Union and How to Fix It. Cambridge and Malden: Polity Press.

Hooghe L and Marks G (2009) 'A Postfunctionalist Theory of European Integration: From Permissive Consensus to Constraining Dissensus', British Journal of Political Science 39: 123.

Jolly M (2007) The European Union and the People. Oxford: Oxford University Press.

Klingermann H-D, Volkens A, Bara J and Budge I (2007) Mapping Policy Preferences Ii: Estimates for Parties, Electors and Governments in Central and Eastern Europe, European Union and OECD 1990-2003. Oxford: Oxford University Press.

König T (2008) 'Analysing the Process of EU Legislative Decision-Making : To Make a Long Story Short...', European Union Politics 9(1): 145-65.

König T, Luetgert B and Dannwolf T (2006) 'Quantifying European Legislative Research: Using Celex and Prelex in EU Legislative Studies ', European Union Politics 7(4): 553-74. 
Leuffen D and Hertz R (2010) 'If Things Can Only Get Worse: Anticipation of Enlargement in European Union Legislative Politics', European Journal of Political Research 49(1): 53-74.

Majone G (2006) Regulating Europe. London: Routledge.

Marks G, Hooghe L, Nelson M and Edwards E. (2004). Party Competition and European Integration in East and West. Different Structure, Same Causality.

Marks G, Hooghe L, Nelson M and Edwards E (2006) 'Party Competition and European Integration in the East and West', Comparative Political Studies 39(2): 155-75.

Marks G and Steenbergen M (eds) (2004) European Integration and Political Conflict. Oxford: Oxford University Press.

McLauren L M (2006) Identity, Interests, and Attitudes to European Integration. London: Palgrave.

Moravcsik A (2002) 'In Defence of the 'Democratic Deficit': Reassessing Legitimacy in the European Union', Journal of Common Market Studies 40(4): 603-24.

Page E and Dimitrakopoulos D (1997) 'The Dynamics of EU Growth. A Cross-Time Analysis ', Journal of Theoretical Politics 9(3): 365-87

Pfaff B (2008) 'Var, Svar and Svec Models: Implementation within R Package Vars', Journal of Statistical Software 27(4): 1-32.

Schmitt H and Thomassen J J A (2000) 'Dynamic Representation: The Case of European Integration', European Union Politics 1(3): 318-39.

Schulz H and König T (2000) 'Institutional Reform and Decision-Making Efficiency in the European Union', American Journal of Political Science 44(4): 653-66. 
Selck T, Rhinard M and Häge F (2007) 'The Evolution of European Legal Integration', European Journal of Law and Economics 24(3): 187-200.

Warntjen A (2007) 'Steering the Union. The Impact of the EU Presidency on Legislative Activity in the Council', Journal of Common Market Studies 45(5): 1135-57.

Warntjen A, Hix S and Crombez C (2008) 'The Party Political Make-up of EU Legislative Bodies", Journal of European Public Policy 15(8): 1243-53.

Wessels W (1995) 'Evaluations of the Ec: Elite or Mass-Driven', in O Niedermayer and R Sinnott (eds) Public Opinion and Internationalized Governance. Oxford: Oxford University Press.

Wlezien C (1995) 'The Public as Thermostat - Dynamics of Preferences for Spending', American Journal Of Political Science 39(4): 981-1000.

Wlezien C (2004) 'Patterns of Representation: Dynamics of Public Preferences and Policy', The Journal of Politics 66(1): 1-24. 
Figure 1. Relationships between economic conditions, public opinion, party positions, and policy change. Solid arrows represent links for which evidence from studies of the EU exists, while dotted arrows represent hypothesized relationship for which only anecdotal or comparative evidence from the US is available.

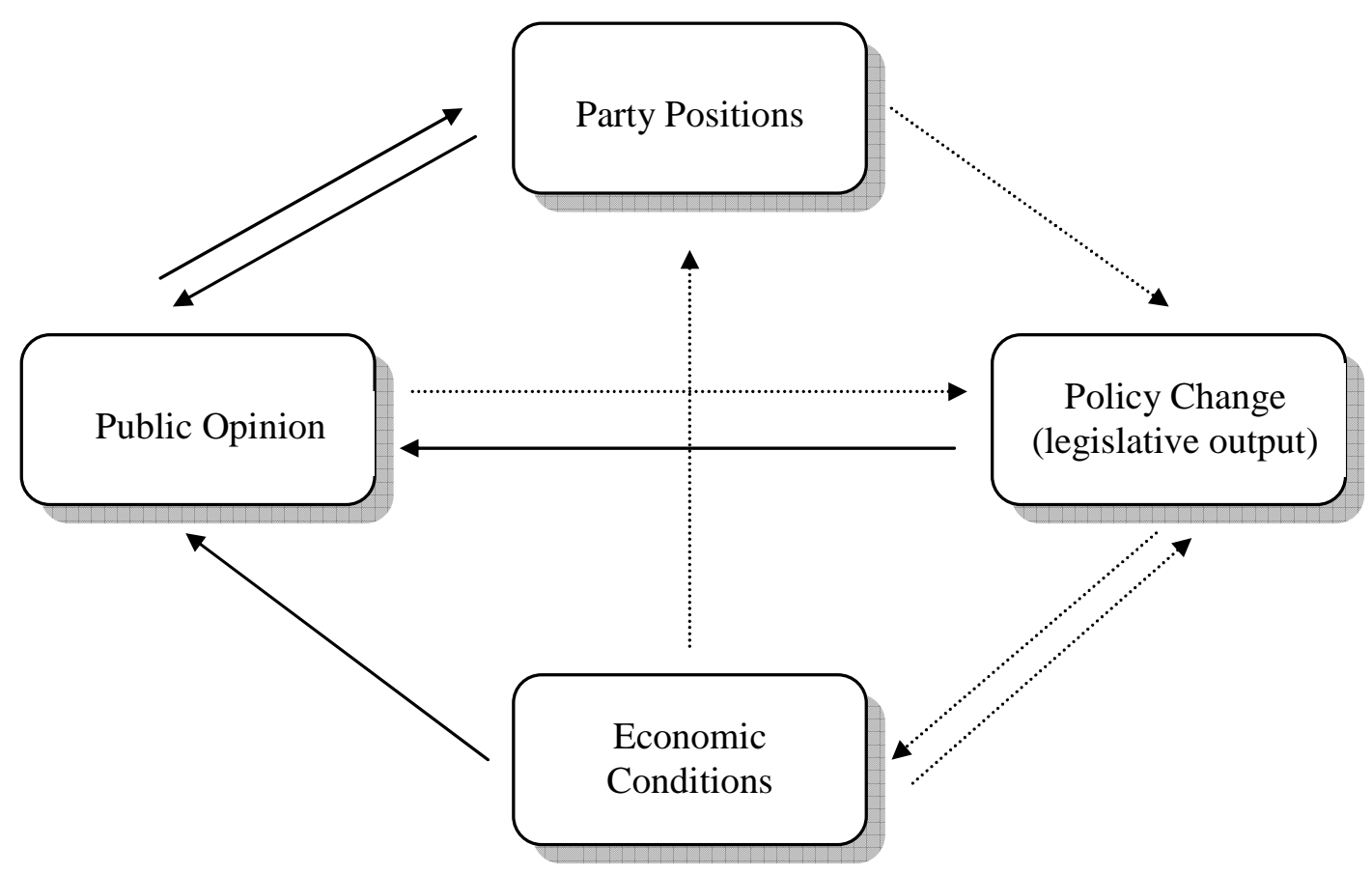


Figure 2. Legislative output, public support, government preferences for integration, and unemployment in the European Union (1973-2008).

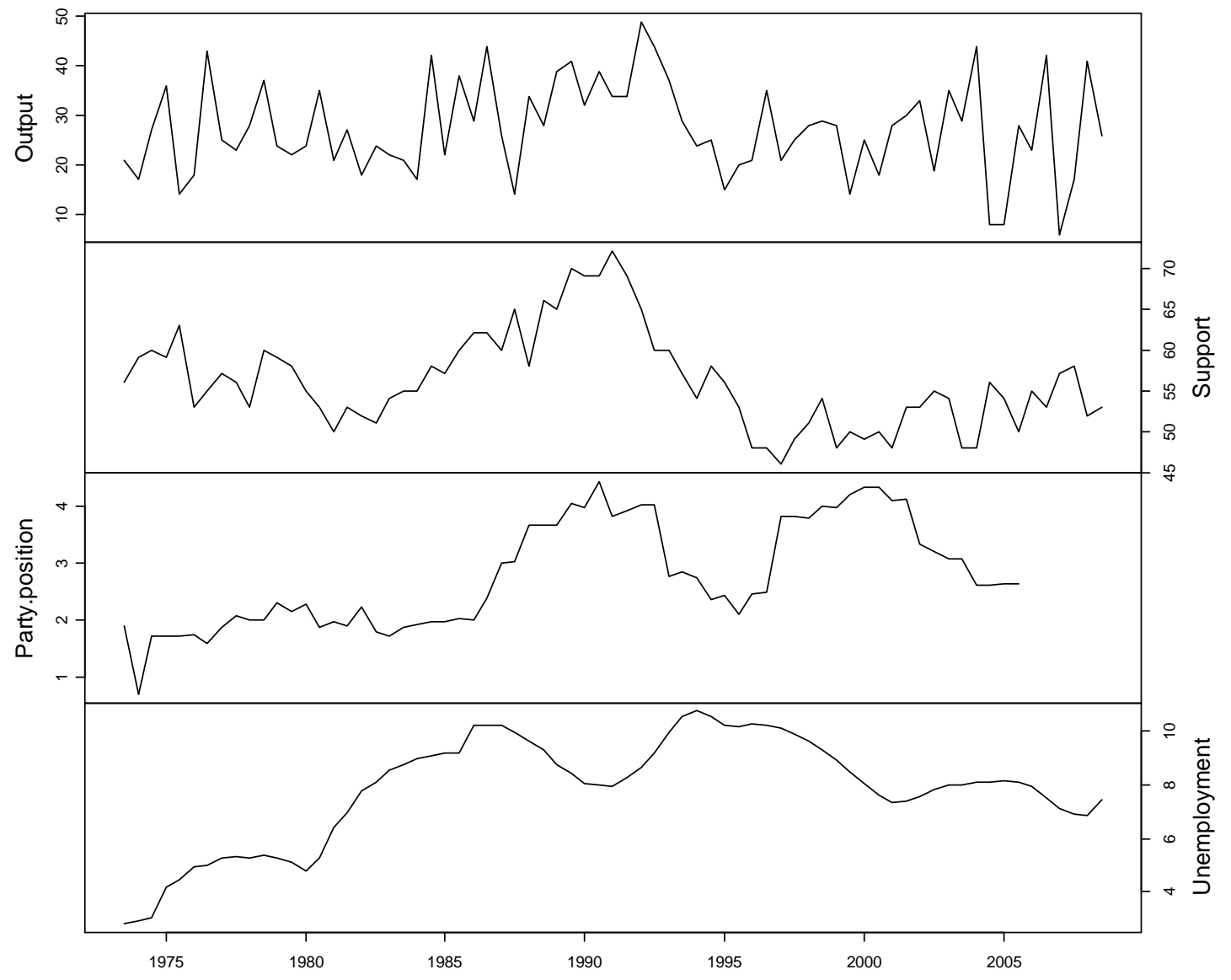


Figure 3. Public support for integration and legislative output: time series plot and cross-correlation function.
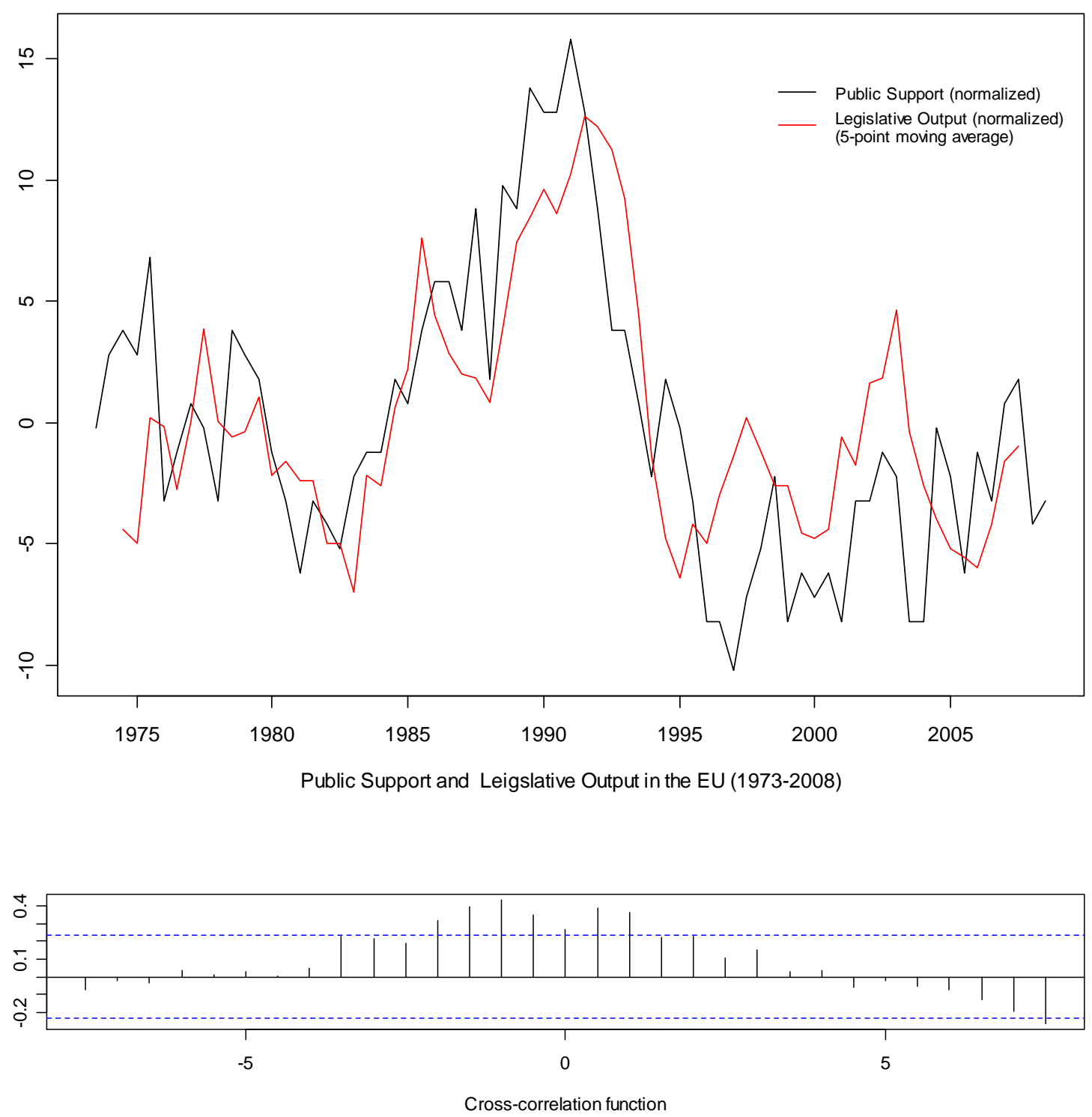
Figure 4. Impulse response functions: public support and legislative output.

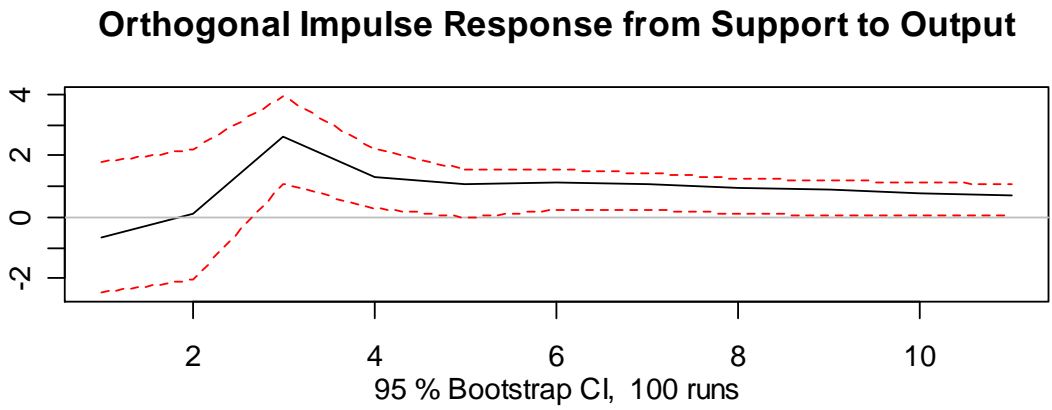

Orthogonal Impulse Response from Output to Support

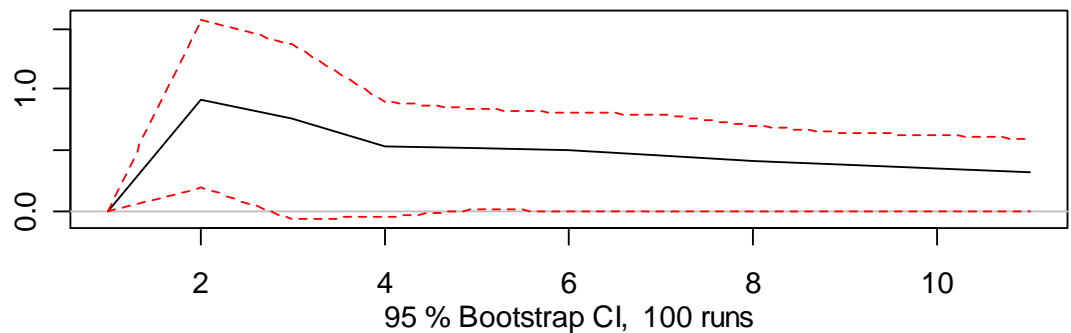

Table 1. OLS estimates ( $\mathrm{t}$-values in parenthesis).

Public Support Legislative Output

$\begin{array}{lll}\text { Public Support }_{t-1} & 0.62(5.1) * * * & 0.02(0.7)\end{array}$



Public Support $t-2$
$0.16(1.4)$
$0.78(2.4) *$
Legislative Output $_{t-1}$
$0.10(2.3) *$
$-0.09(-0.8)$
Legislative Output $_{t-2}$
$0.03(0.7)$
$-0.09(-0.8)$

Table 2. Granger Causality Tests based on a VAR(2) model.

\begin{tabular}{lrcc} 
Exogenous variable & Restricted coefficients & F statistic & p-value \\
& & & \\
\hline Public Support & Legislative Output & 8.39 & 0.0005 \\
Legislative Output & Public Support & 3.09 & 0.0523
\end{tabular}

Table 3. Granger Causality Tests in the system.

Effect on: Public Support Leg Output Unemployment Party Positions

\section{Cause}

\begin{tabular}{lcccc}
\hline Public Support & & $6.17 * * *$ & 0.36 & 1.16 \\
Leg Output & 1.02 & & 2.36 & 0.66 \\
Unemployment & 0.22 & 0.11 & & $5.05 * * *$ \\
Party Positions & 0.31 & 0.98 & 0.13 &
\end{tabular}

Results from bivariate Granger Causality Tests. Numbers in the cells are F statistics. Significant pvalues at the 0.01 level are marked $* * *$. 
